\title{
An assessment of the iodine and selenium content of cow's milk produced in Northern Ireland
}

\author{
S.M. O’Kane ${ }^{1}$, L.K. Pourshahidi ${ }^{1}$, M.S Mulhern ${ }^{1}$, R.R. Weir ${ }^{1}$, S. Hill ${ }^{2}$, J. O'Reilly ${ }^{2}$, \\ D. Kmiotek ${ }^{2}$, C. Deitrich ${ }^{2}$, E.M. Mackle ${ }^{1}$, E. Fitzgerald ${ }^{1,3}$, J.J. Strain ${ }^{1}$ and A.J. Yeates ${ }^{1}$ \\ ${ }^{1}$ Northern Ireland Centre for Food and Health (NICHE), University of Ulster, Cromore Road, Coleraine, BT52 1SA, \\ ${ }^{2}$ LGC Queens Road, Teddington, Middlesex TW11 OLY and ${ }^{3}$ Athlone Institute of Technology, Dublin Road, Athlone, \\ Co. Westmeath, Ireland
}

Cow's milk is the most important dietary source of iodine and it also contributes to dietary selenium intakes in many European countries, including the UK and Ireland ${ }^{(1-4)}$. Iodine and selenium are necessary for the maintenance of thyroid hormone homeostasis and have important roles in growth and development ${ }^{(5)}$. While the UK and Ireland were historically thought to be iodine sufficient, emerging evidence shows that many of the population are now iodine deficient ${ }^{(6,7)}$. The aim of the present study was to investigate the effect of season, milk fat class and pasteurisation on iodine and selenium concentrations in Northern Ireland (NI) milk.

Milk samples (unpasteurised, whole, semi-skimmed and skimmed) were collected from two large NI creameries between May 2013 and April 2014. Monthly samples of each milk type were analysed by inductively coupled plasma-mass spectrometry (ICP-MS) for iodine and selenium content.

Table 1. outlines the iodine and selenium concentrations according to milk fat class, stage of pasteurisation and season.

\begin{tabular}{|c|c|c|c|c|c|c|c|c|}
\hline & & $n$ & Mean iodine concentration $(\mu \mathrm{g} / \mathrm{kg})$ & SD & $P^{*}$ & Mean selenium concentration $(\mu \mathrm{g} / \mathrm{kg})$ & SD & $P^{*}$ \\
\hline \multirow[t]{3}{*}{ Milk Fat Class } & Skimmed & 12 & $472 \cdot 6$ & $76 \cdot 0$ & & $18 \cdot 5$ & $2 \cdot 0$ & \\
\hline & Semi-Skimmed & 12 & $466 \cdot 6$ & $62 \cdot 6$ & 0.696 & $17 \cdot 6$ & $3 \cdot 3$ & 0.539 \\
\hline & Whole & 12 & $488 \cdot 5$ & $53 \cdot 3$ & & $17 \cdot 2$ & $2 \cdot 8$ & \\
\hline \multirow[t]{2}{*}{ Pasteurisation } & Pasteurised $\dagger$ & 36 & $475 \cdot 9$ & $63 \cdot 5$ & & $17 \cdot 8$ & $2 \cdot 7$ & \\
\hline & Unpasteurised $\$$ & 12 & $451 \cdot 7$ & $71 \cdot 9$ & $0 \cdot 275$ & $18 \cdot 4$ & $2 \cdot 0$ & 0.43 \\
\hline \multirow[t]{4}{*}{ Season $\dagger$} & Winter & 9 & $498 \cdot 1^{\mathrm{a}, \mathrm{b}}$ & $30 \cdot 6$ & $<0 \cdot 001$ & $17 \cdot 8$ & $2 \cdot 8$ & $0 \cdot 180$ \\
\hline & Spring & 9 & $534 \cdot 3^{\mathrm{a}}$ & $53 \cdot 7$ & & $18 \cdot 8$ & 2.4 & \\
\hline & Summer & 9 & $437 \cdot 4^{\mathrm{b}, \mathrm{c}}$ & $48 \cdot 9$ & & $16 \cdot 1$ & $2 \cdot 5$ & \\
\hline & Autumn & 9 & $433.6^{\mathrm{c}}$ & 57.8 & & $18 \cdot 4$ & $2 \cdot 9$ & \\
\hline
\end{tabular}

* $P$ value for comparison between groups from independent $t$ test or one-way ANOVA

+ Mean of skimmed, semi-skimmed and whole milk samples

\$ Samples were collected pre-pasteurisation and pre-homogenisation

a,b,c values within a column with different superscript letters represent significance $(P<0.05)$.

This study provides an updated assessment of iodine and selenium concentrations in NI produced cow's milk. Season was found to have an important determining effect on the iodine, but not the selenium, content of cow's milk. The observed seasonal variation in iodine is likely to reflect the change in animal feeding practices across seasons ${ }^{(8)}$. Iodine and selenium concentrations in milk were not affected by the milk fat class or by pasteurisation. The iodine and selenium concentrations reported in this study are higher than those listed in food composition databases highlighting the need for further analysis to update these data ${ }^{(9)}$. As cow's milk is the main dietary source of iodine in the UK and Ireland, the seasonal variation in the iodine content of milk is likely to impact iodine intake and thus status across the year.

1. Bates et al. (2014) National Diet and Nutrition Survey

2. Rasmussen et al. (2002) Br J Nutr. 87 (1): 61-69.

3. Dahl et al. (2003) Public Health Nutr. 7 (4):569-576.

4. Food Safety Authority of Ireland (2011) Report on a Total Diet Study.

5. Arthur \& Beckett (1999) Brit Med Bull 55 (3): 658-668.

6. Nawoor et al. (2006) Ir J Med Sci 175 (2): 21-24.

7. Vanderpump et al. (2011) Lancet 377 (9782): 2007-2012.

8. Flachowsky et al. (2014) Eur J Nutr $\mathbf{5 3}$ (2): 351-365.

9. Food Standards Agency (2015) McCance and Widdowson's The Composition of Foods. 